\title{
Examination Committee Work Management System
}

\author{
Abdul Aziz Suleiman Turfa Y. Hamed Nadia T. Saleh \\ College of Computer Science and Mathematics \\ University of Mosul, Iraq
}

Received on: 04/07/2006

\section{ABSTRACT}

Accepted on: 04/10/2006

The aim of this paper is to design a software for examination committee work management using Visual FoxPro programming language, which is considered as one of the most popular and useful visual programming languages that supports Database Management System (DBMS).

This software is designed to facilitate the management of examination committee work to assist the documentation for the important data like card files and records and to retrieve examination information.

The software has the ability to display the students' marks after data insertion. These data are gained from Microsoft Excel tables. In addition, the software could compute the annual total marks, the final marks, the average, and the estimation. Besides it could search the database for a specified student name. The students' marks, the final results, and the sequence and estimation for passed students could be organized as a printing material. Also the software gives printed reports for first semester, midyear, second semester, and annual total marks, for all studied subjects of a specified stage and according to that stage classes. In addition to the capability of statistical computing for the pass ratio, total number of students and the number of passed students according to the stage, with printed capabilities.

Keywords: Database Management System, Visual FoxPro programming language, Microsoft Excel.

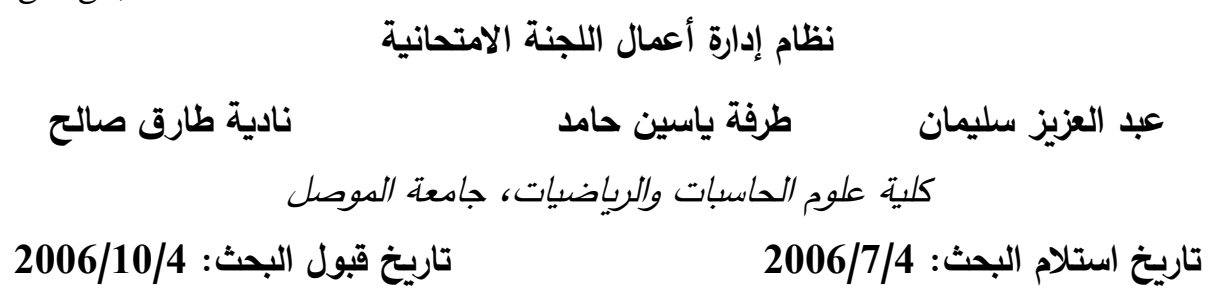




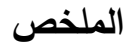

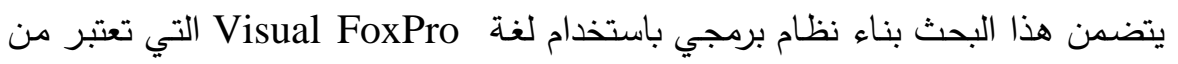

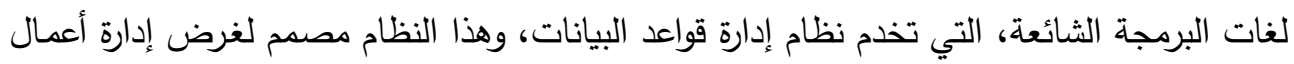

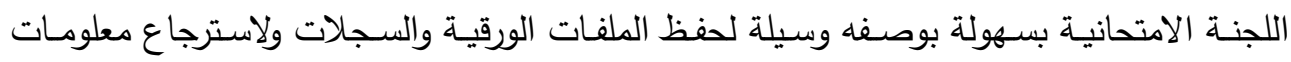

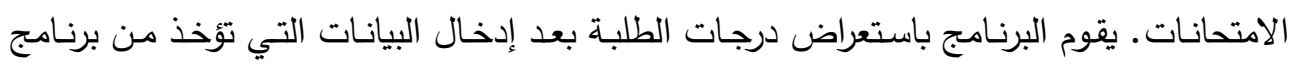
Microsoft Excel

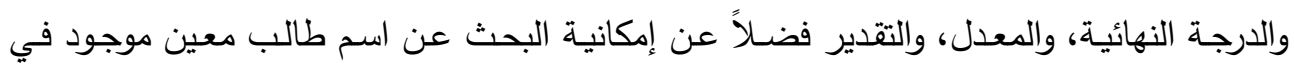

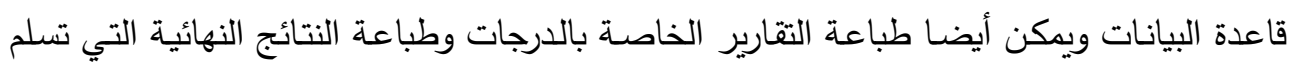

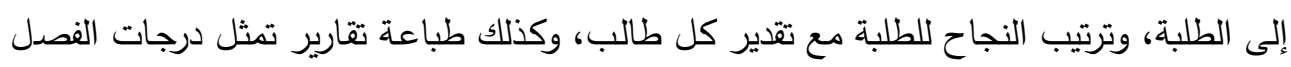

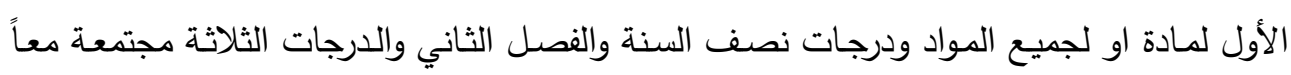

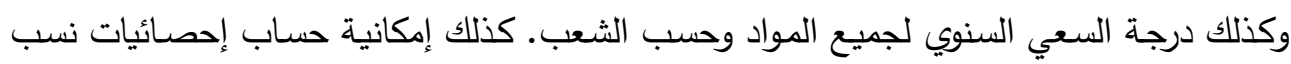

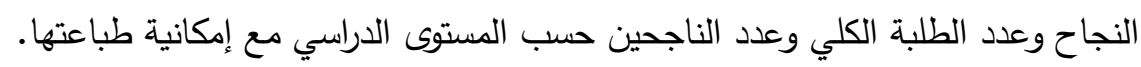

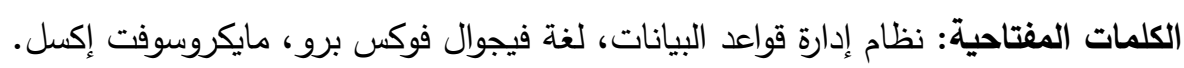

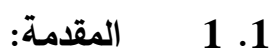

إن إدارة التعليم بالحاسب Computer Managed Instruction ( ) لا تعني استخدام الحاسب الآلي في التعليم أو التدريس فقط ولكن الذي تعنيه هو إدارة العملية التعليمية بداخل المرفق

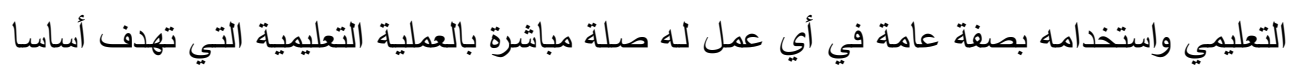
إلى تحسين مستوى التعليم وزيادة فاعليته [4]. ويككن إيجاز استخدامات الحاسب في العملية التربوية التعليمية في ثلاث طرائقائق مختلفة يمكن تحديدها على النحو الأتي:

1- الحاسب مادة تعليمية. Subject Matter

Computer Managed Instruction (CMI) - الحاسب مساعد في إدارة العطلية التعليمية،

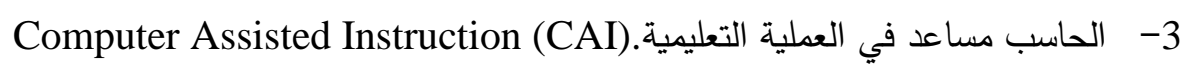
وسيتم التطرق إلى النوع الثاني من الاستخدامات كونه موضوع البحث:

2. 1 الحاسب مساعد في إدارة العملية التعليمية Computer Managed Instruction 


\section{:(CMI)}

يثير الباحثون إلى أن استخدام الحاسب يقتصر على القيام بعدد من الوظائف ذات الارتباط المباشـر بالعملية التعليميـة. ومـن هذه الوظـائف: تقديم الاختبـارات للطـلاب، وتصـيحها. ويسهم الحاسب أيضـاً في تقديم صورة لما استوعبه الطلاب بعد دراستهم لوحدة معينة، وغالباً مـا تكون الاختبارات من نوع الاختيار من متعدد تحتاج إلى إجابات قصيرة محددة . وبعد انتهاء الطالب من الاختبار يقوم الحاسب بكتابة تقرير عن مستوى الطالب، وأدائه

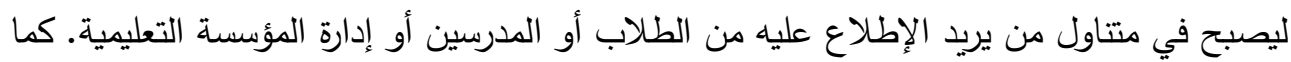
يمكن للحاسب أن يحتفظ بمعلومات متكاملة عن كل طالب يتضمن اسم الطالب، ورقمه، ودرجاته

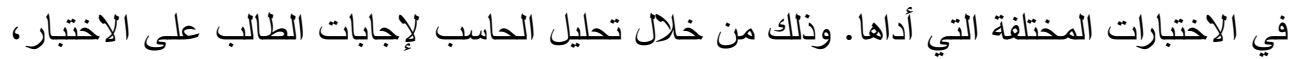
أو عن طريق البيانات التي يزوده بها المدرس. ويضاف إلى ذلك أنه يمكن استخدام الحاسب في تقديم وصفات تعليمية لكل طالب، كأن

يحـد موضـوعات ينبغـي للطالب إعـادة تعلمهـا، وذلك مـن خـلال عمليـة التوجيـهـ Routing. ويلاحظ أن استخدام الحاسـب في هذا المجال يمكن أن يخفف من الأعمال الروتينية، والأعباء الإدارية التي يقوم بها المدرس، مما قد يتيح لـه الفرصـة لمتابعة الطلاب الموهوبين، والطلاب الذين

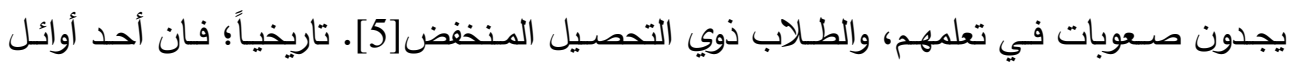
الطرائق التي استخدم الحاسب فيها بنجاح في الدول المتقدمة كانت في المجال التعليمي وفي إدارة المؤسسة التعليمية أيضـاً. وعلى الرغم من اختلاف الأسـاليب والتقنيات المستخدمة فان استخدام الحاسب في التعليم ما زال قائماً إلى الآن [6].

\section{1 مقدمة إلى نظام إدارة أعمال اللجنة الامتحانية:}

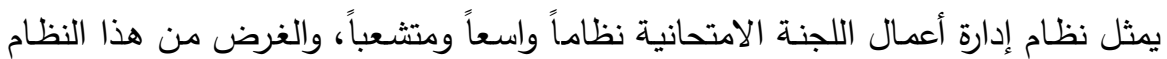
هو تسهيل التعامل مع قواعد البيانات الخاصة بالطلبة، ومن هذه البيانات على سبيل المثال أسماء

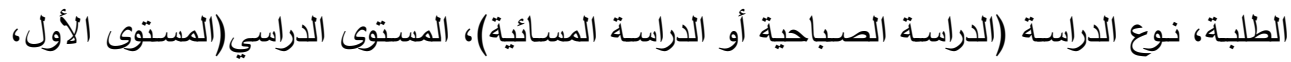

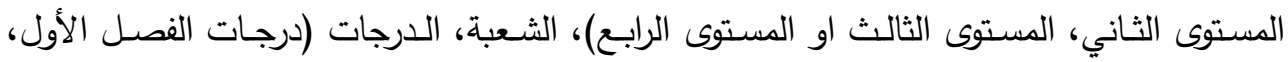
درجات نصف السنة ودرجات الفصل الثاني). 
ويمكن من خلال البرنامج القيام بعملية البحث عن اسم طالب معين، وإجراء الإحصائيات

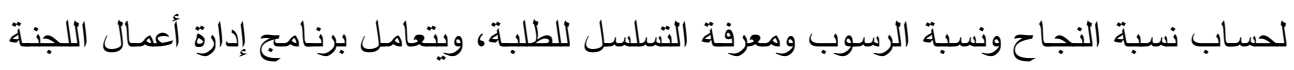

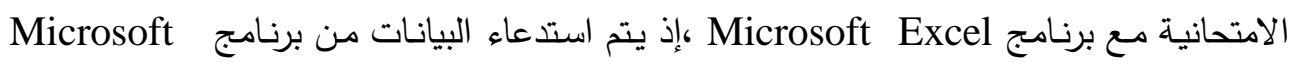

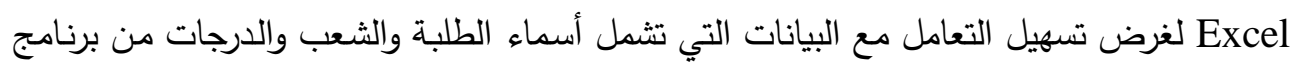
Microsoft Excel

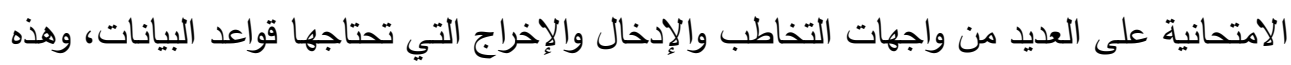

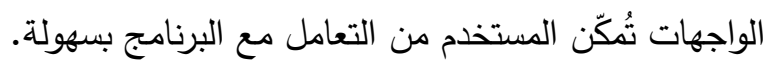

4. 1 تثغيل برنامج إدارة أعمال اللجنة الامتحانية:

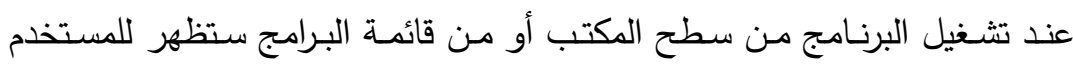

الواجهة الرئيسية كما في الثشاشة (1):

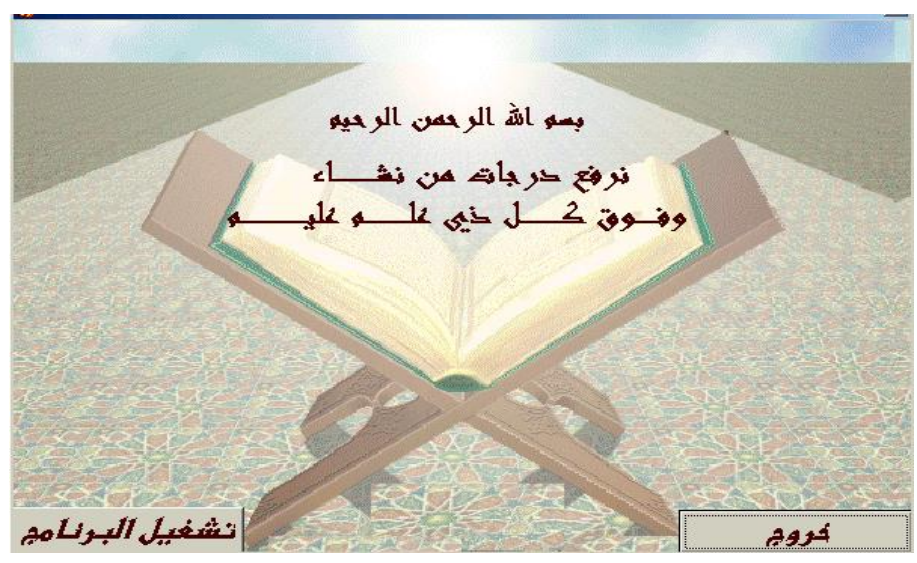

\section{الثناشة (1) الواجهة الرئيسية}

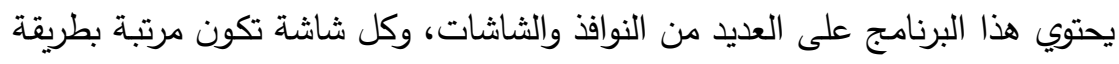

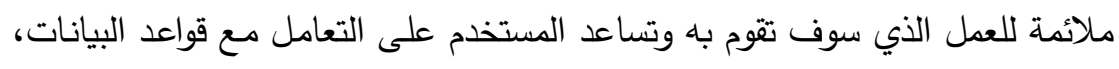

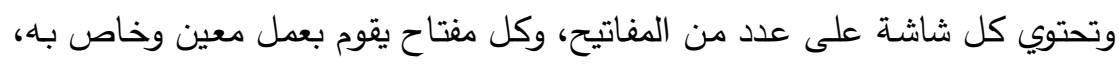

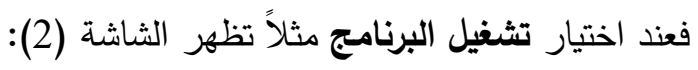




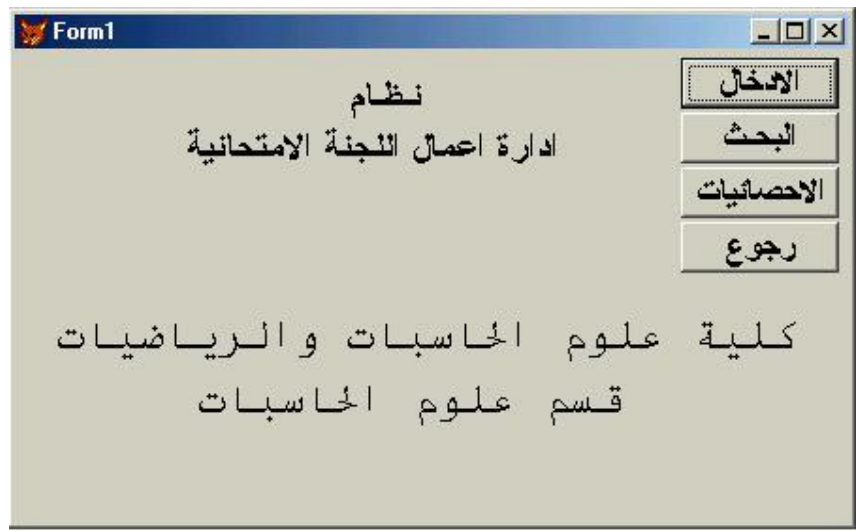

الثاشة (2) اختيارات النظام

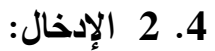

عند النقر على مفتاح الإدخال الموجود في الثاشـة (2) يتم استدعاء نافذة أخرى كما هو

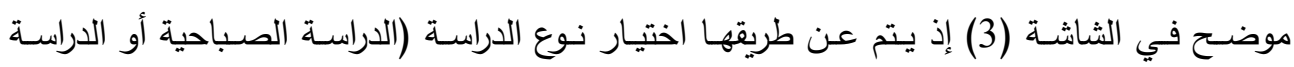

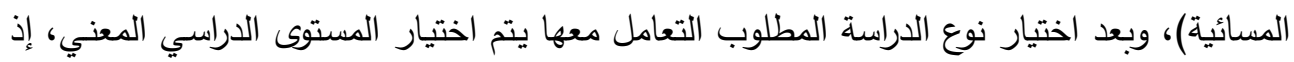
يتم النقر أولاً على المفتاح صباحي أو مسائي ثم يتم النقر على أحد المستويات: المستوى الأول، المستوى الثاني، المستوى الثالث، المستوى الرابع، وبهذا يتم اختيار الدراسة والمستوى المطلوب.

\section{Ex Form1}

اخثيار ألدر أسية و المر حلة

صباحي

مسباحي

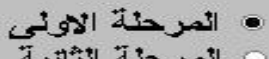

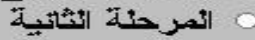

ا انمرحية انثيثة

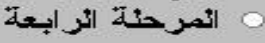

ع 
الثاشة (3) اختيار الدراسة والمستوى الدراسي

5. 5ريقة التعامل مع المستوى الدراسي:

عند اختيار أي مستوى من المستويات الدراسية تظهر الثاشة (4). تعتبر هذه الثاشة

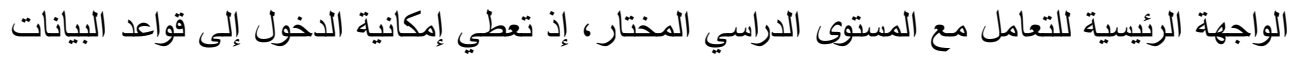

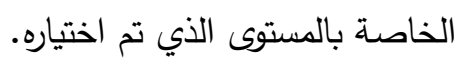

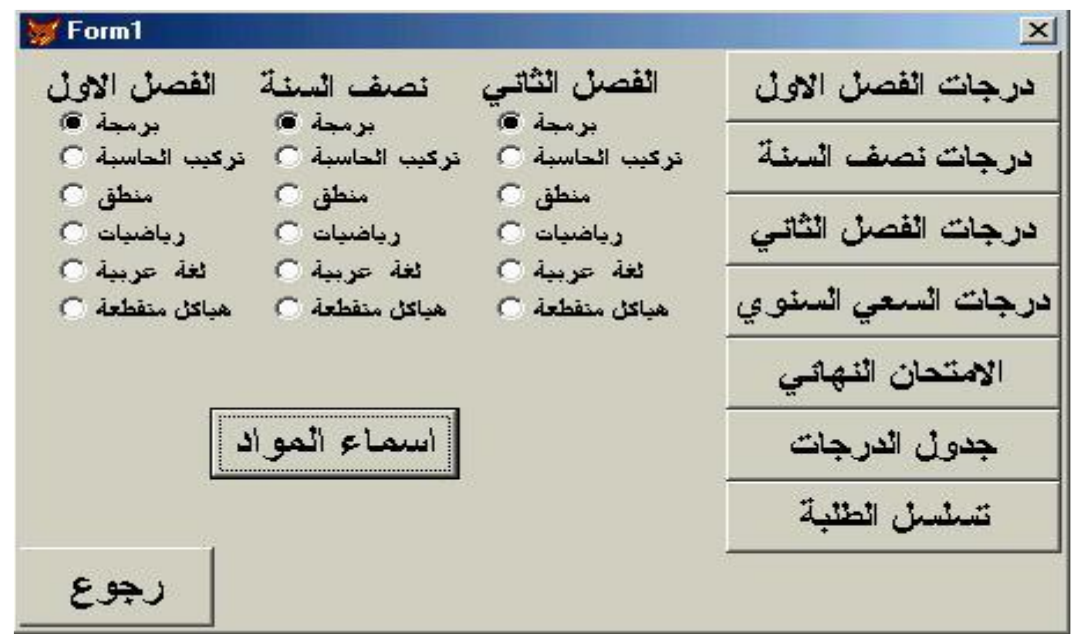

الثاشة (4) توضح الواجهة الرئيسية لكل مستوى دراسي

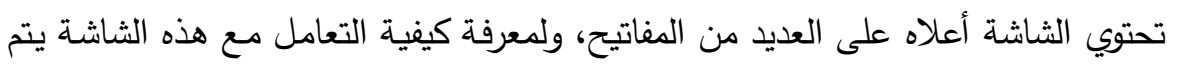

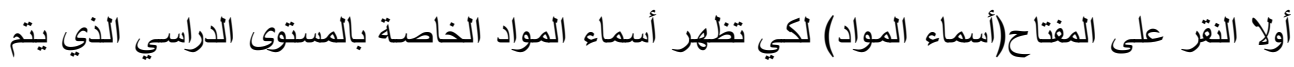

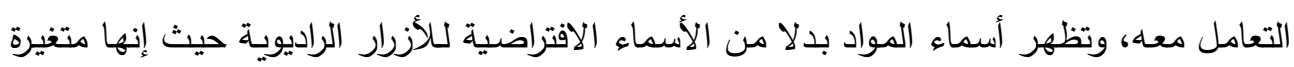

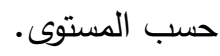

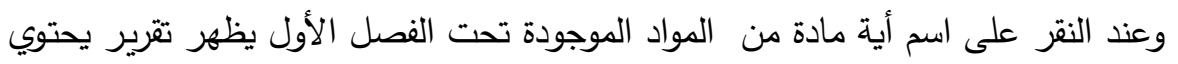

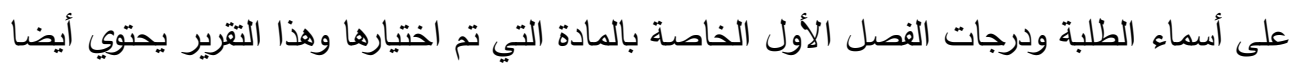


على اسم المـادة والثعبة، ويمكن طباعة هذا التقرير على الطابعة مباشرة لغرض عرض درجات الفصل الأول الخاصة بكل مادة يتم اختيارها كما في الثاشة (5):

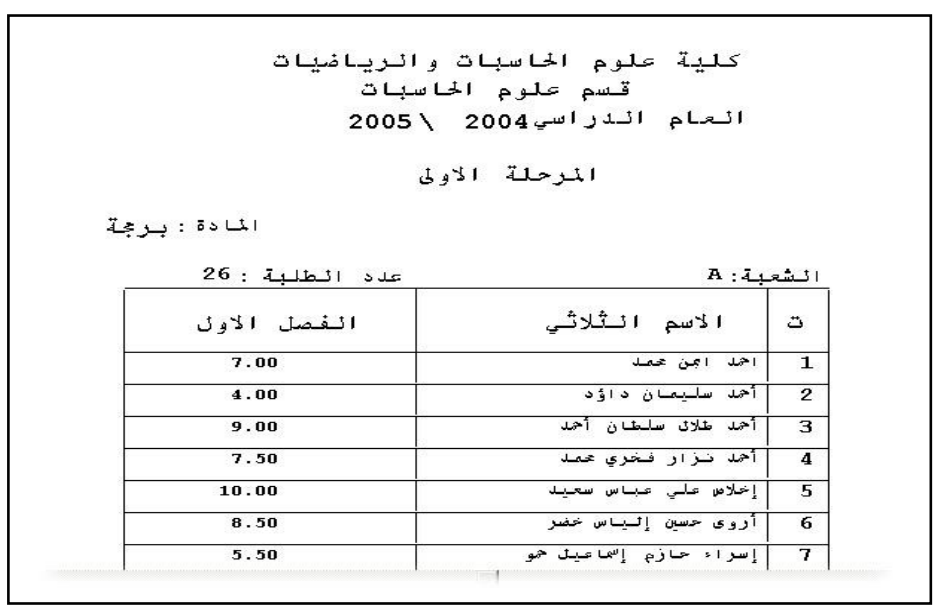

\section{الثاشة (5) توضح تقرير درجات الفصل الأول لمادة واحدة}

أمـا عنــد اختيار اسـ أي مـادة مـن المـواد الموجودة تحـت الحقل (نصـف السـنة) فيتم الحصول على تقرير يحتوي على أسماء الطلبة الخاصـة بكل شعبة ودرجات نصف السنة لتلك

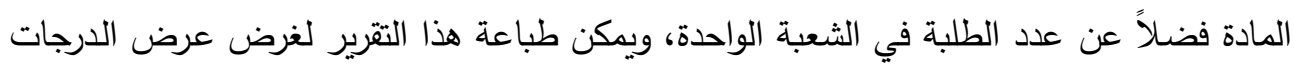
الخاصة بكل مادة من المواد كما في الثكل السابق لكن مع اختلاف درجة نصف السنة بدل الفصل الأول.

وعند اختيار اسم أية مـادة من المواد التي تقع تحت الفصل الثاني يتم الحصـول على التقرير الخاص بالمادة المختارة وهو يحتوي على أسماء طلبة كل شعبة ودرجات الفصل الثاني لتلك المادة وعدد طلبة تلك الثعبة. أما إذا تم النقر على المفتاح الذي اسمه (درجات الفصل الأول) وهو موجود في الجهة العليا اليمنى من الثاشـة (4) فيظهر تقرير يحتوي على أسماء الطلبة ودرجات الفصل الأول لكل المواد الدراسية والثعبة وعدد الطلبة في الثعبة الواحدة، كما في الثاشة (6): 


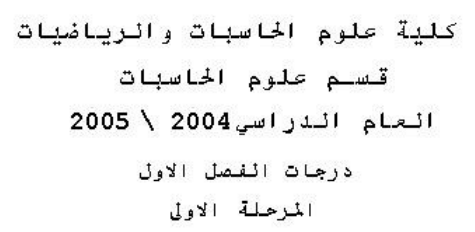

\begin{tabular}{|c|c|c|c|c|c|c|c|}
\hline 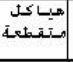 & عربية & ريـانيات & هـنطق & تحساسبية & |برئة & الاسـمـ الـثخلاثشي & 0 \\
\hline 0.00 & 0.00 & 0.00 & 0.00 & 0.00 & 7.00 & | & 1 \\
\hline 5.50 & 4.00 & 4.00 & 4.00 & 4.00 & 4.00 & أ أحدل سلـيدهان داؤود & 2 \\
\hline 8.50 & 9.00 & 9.00 & 9.00 & 9.00 & 9.00 & أحتد طلاثل سلـطان أحدا & 3 \\
\hline 7.50 & 7.50 & 7.50 & 7.50 & 7.50 & 7.50 & 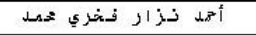 & 4 \\
\hline 7.00 & 10.00 & 10.00 & 10.00 & 10.00 & 10.00 & إخلاس عملي عبداس سعيد & 5 \\
\hline 8.00 & 8.50 & 8.50 & 8.50 & 8.50 & 8.50 & أروى مسين إلدياس سرضر & 6 \\
\hline 8.00 & 5.50 & 5.50 & 5.50 & 5.50 & 5.50 & إسر اء حسا زم إلماعيدل حمو & 7 \\
\hline
\end{tabular}

الثاشة (6) توضح تقرير درجات الفصل الأول لكل المواد

5. 1 التعامل مع درجات نصف السنة:

عند النقر على المفتاح (درجـات نصـف السـنة) الموجود في الثاشـة (4) تظهر شاشـة

أخرى كما موضح في الثاشة (7):

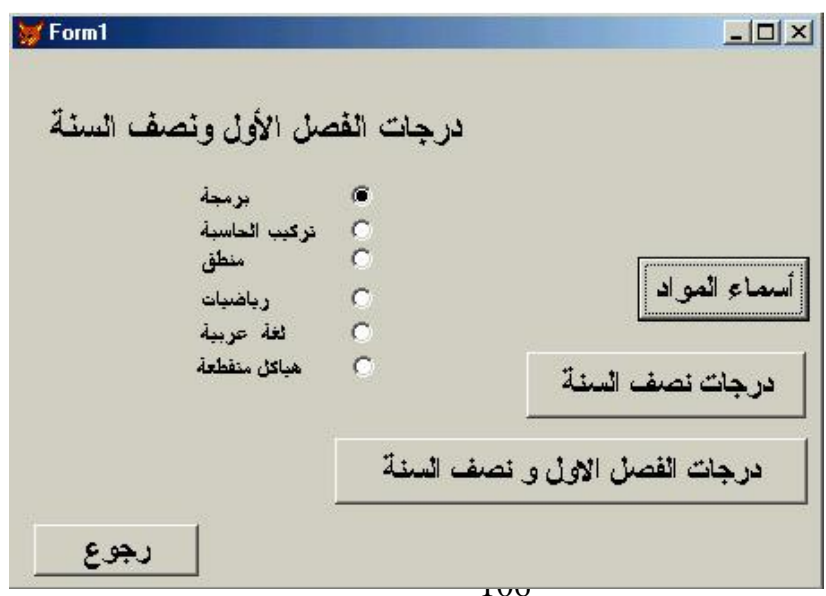




\section{الشاشة (7) اختيار المادة في نصف السنة}

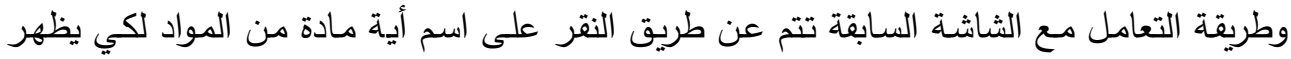
تقرير يحتوي على أسماء الطلبة واسم المادة التي تم النقر عليها ودرجات الفصل الأول ودرجات

نصف السنة لتلك المادة كما في الشاشة (8):

\begin{tabular}{|c|c|c|c|}
\hline \multicolumn{4}{|c|}{ 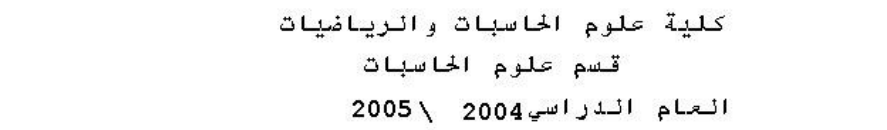 } \\
\hline 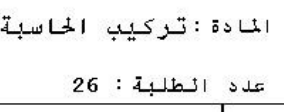 & \multicolumn{3}{|c|}{ انشعبـات : } \\
\hline نـصف الـســة & التــصل الاون & الاسـم اثـثلاثـي & 0 \\
\hline 8.00 & 8.00 & |احد ايمن عمد & 1 \\
\hline 11.50 & 4.00 & أحمد سـلـيــان داؤد & 2 \\
\hline 15.50 & 9.00 & أحمد طلأ سلطان أحمد & 3 \\
\hline 15.50 & 7.50 & أحمد نـز ار فهري يحسل & 4 \\
\hline 17.50 & 10.00 & | إخلامر علـي عباساس سعيدل & 5 \\
\hline 18.00 & 8.50 & |أروى حسنِ إثليا سل خضر & $\overline{6}$ \\
\hline 14.00 & 5.50 & 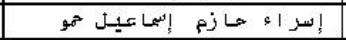 & 7 \\
\hline 19.50 & 10.00 & أسرين جلال إذليـاس أسود & 8 \\
\hline 20.00 & 9.50 & 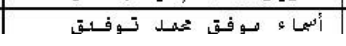 & 9 \\
\hline
\end{tabular}

الشاشة (8) توضح تقرير درجات نصف السنة والفصل الاول لمادة واحدة

أمـا إذا تم النقر على المفتاح (درجـات نصف السـنة) فيظهر تقرير يحتوي على أسماء الطلبة ودرجات نصف السنة بجميع المواد، فضلاً عن الشعبة وعدد الطلبة.

وعند النقر على المفتاح (درجات الفصل الأول ونصف السنة) يظهر تقرير يحتوي على ودئ وعن أسماء الطلبة ودرجات الفصل الأول ونصف السنة لكل المواد. ويحتوي التقرير أيضـاً على الثـعبة وعدد الطلبة، ويعطي البرنـامج إمكانيـة طباعـة أي وني تقرير من التقارير السابقة التي تم الحصول عليها. 
ولغرض الرجوع إلى الثاشة الرئيسية الخاصة بالمستوى الدراسي الذي يتم التعامل معه يتم

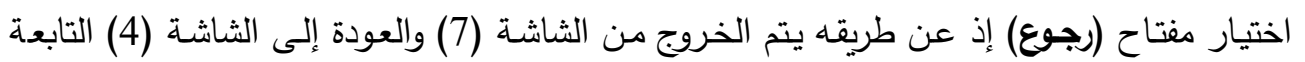
لذلك المستوى الدراسي. 6. التعامل مع درجات الفصل الثاني: عند النقر على مفتاح (درجات الفصل الثاني) الموجود في الثاشة (4) يتم استدعاء شاشـة أخرى، كما موضح في الثاشة (9):

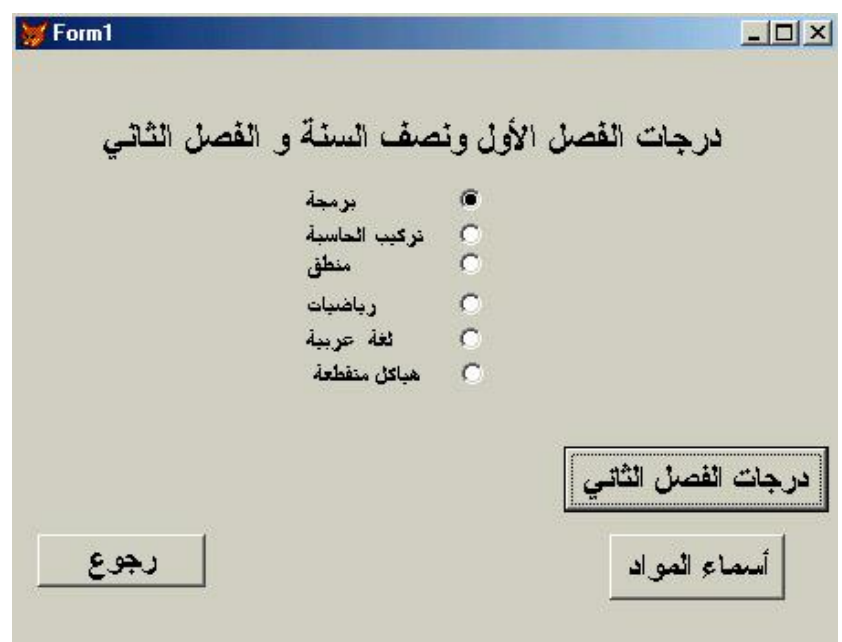

$$
\text { الثاشة (9) اختيار المادة في الفصل الثاني }
$$

وعند اختيار اسم أية مادة من المواد يتم الحصول على تقرير يضم درجات الفصل الأول

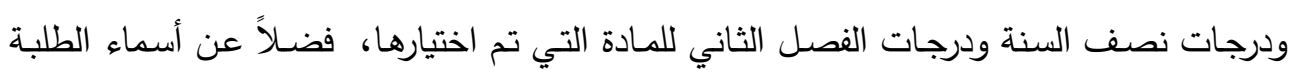
وعددهم واسم تلك المادة كما موضتح في الثاشة (10): 


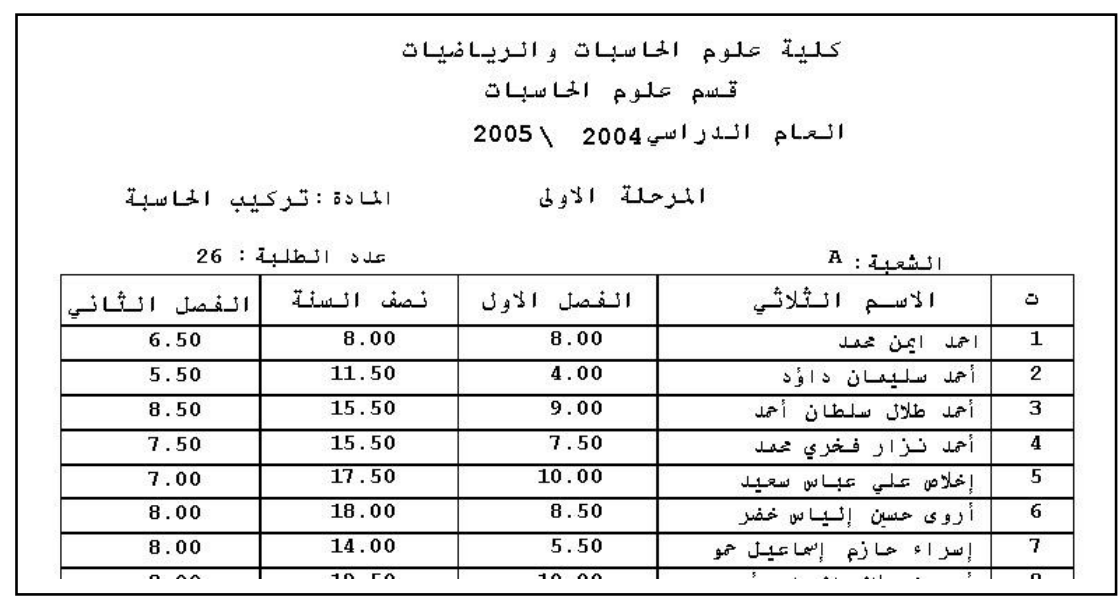

الشاشة (10) توضح تقرير درجات الفصل الأول والثاني ونصف السنة لمادة واحدة

أما عند النقر على مفتاح (درجات الفصل الثاني) الموجود في الثاشة (9) فيظهر تقرير يحتوي على أسماء الطلبة ودرجات الفصل الثاني لكل المواد فضلاً عن الثعبة وعدد الطلبة في كل شعبة كما موضح في الثاشة (11):

\begin{tabular}{|c|c|c|c|c|c|c|c|}
\hline \multicolumn{8}{|c|}{ 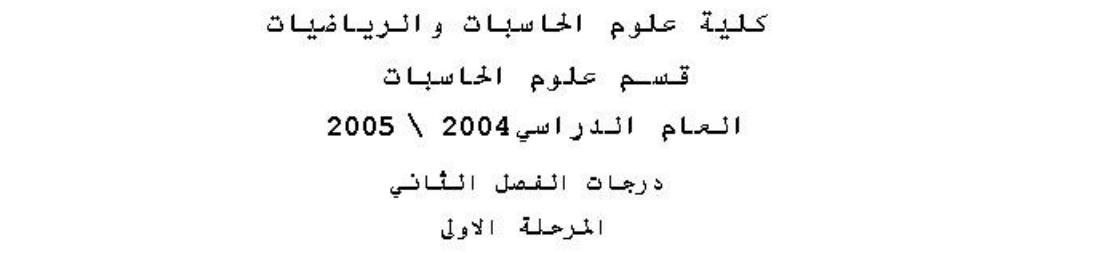 } \\
\hline $26:$ & الـطـلـبـ & 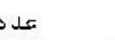 & & & & \multicolumn{2}{|c|}{ السشعبـآ } \\
\hline | & تربيدية & |ريـا نيـات | ريـات & |مسنطق & 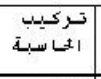 & | & الاســم انـثلاثشي & ت \\
\hline 0.00 & 0.00 & 0.00 & 0.00 & 0.00 & 0.00 & | & 1 \\
\hline 5.50 & 5.50 & 5.50 & 5.50 & 5.50 & 0.00 & أ أحد سلديديان د أؤد & 2 \\
\hline 8.50 & 8.50 & 8.50 & 8.50 & 8.50 & 0.00 & أحمد طلاد سلــلان أحتد & 3 \\
\hline 7.50 & 7.50 & 7.50 & 7.50 & 7.50 & 0.00 & 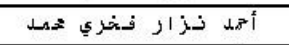 & 4 \\
\hline 7.00 & 7.00 & 7.00 & 7.00 & 7.00 & 0.00 & 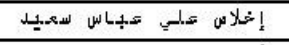 & 5 \\
\hline 8.00 & 8.00 & 8.00 & 8.00 & 8.00 & 0.00 & أروى تمسيز إلـياس خضر & 6 \\
\hline 8.00 & 8.00 & 8.00 & 8.00 & 8.00 & 0.00 & 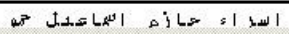 & 7 \\
\hline
\end{tabular}


الثاشة (11) توضح تقرير درجات الفصل الثاني لجميع المواد

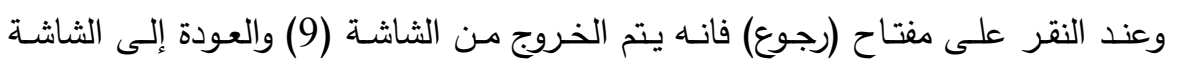

الرئيسية وهي الثاشة (4).

7. - التعامل مع درجات السعي السنوي:

بعد أن تم إدخال درجات الفصل الأول ودرجات نصف السنة الندة ودرجات الفصل الثاني، فان

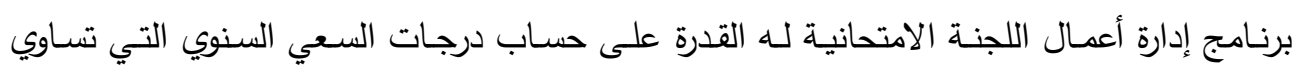

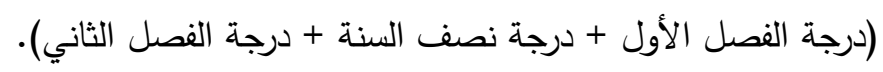

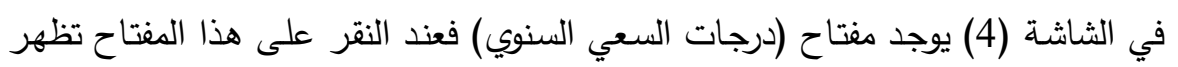

الواجهة الموضحة في الثاشة (12):

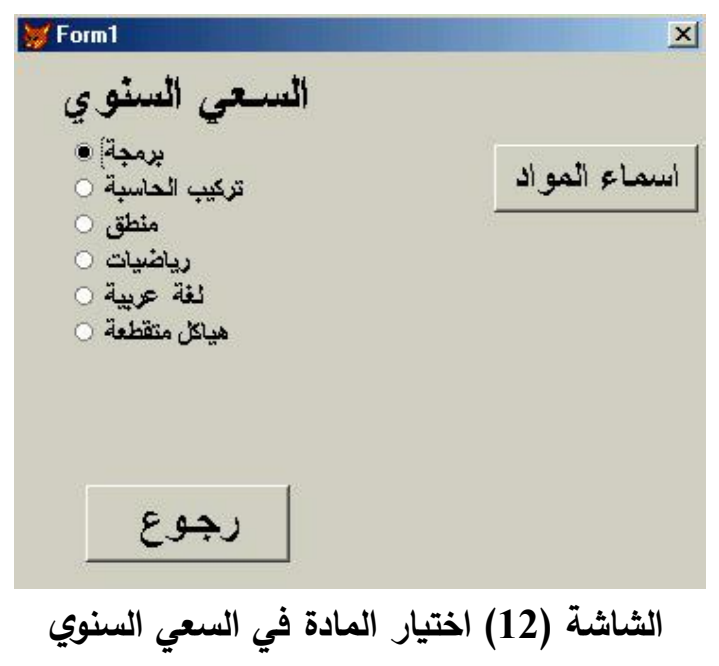

وعند اختيار اسم أية مادة من المواد يتم عرض تقرير يحتوي على أسماء الطلبة والثعبة ودرجات السعي السنوي لتلك المادة التي تم اختيارها.

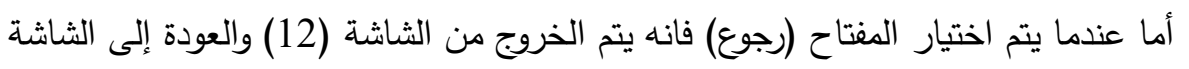

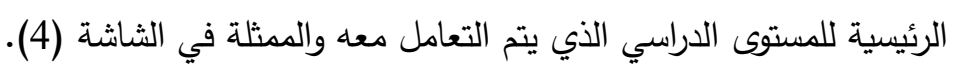




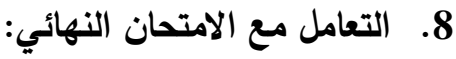

يوجد في الثاشة (4) مفتاح (الامتحان النهائي) وعند النقر عليه يتم استدعاء الثاشة

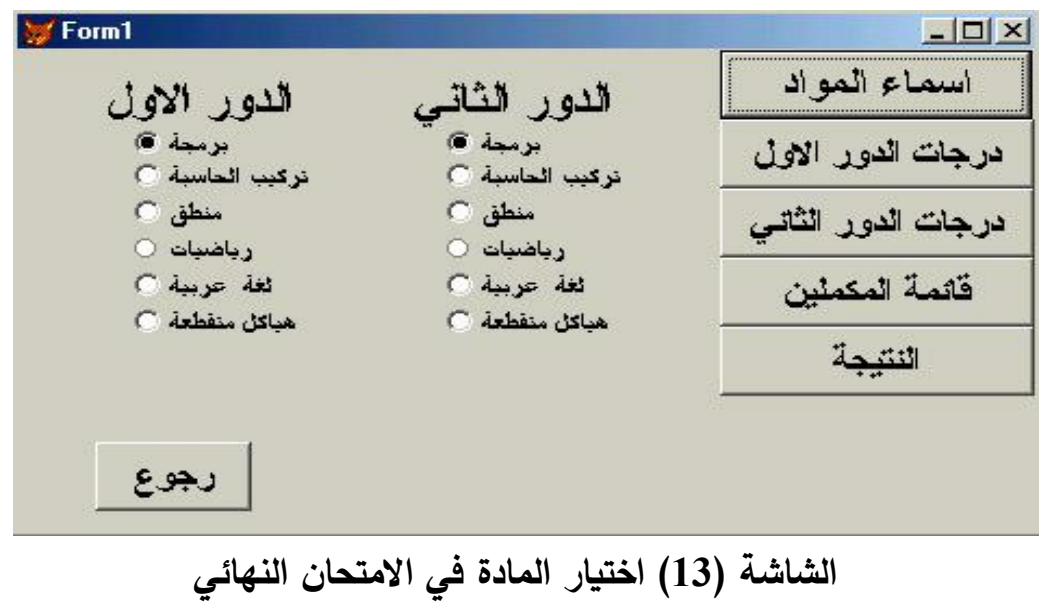

عند اختيار اسم أية مادة من المواد التي تقع تحت الدور الأول يتم عرض تقرير يحتوي

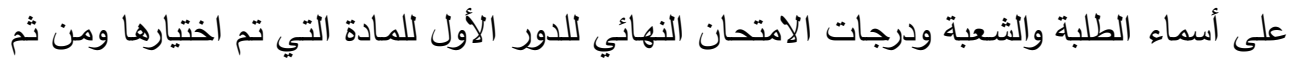

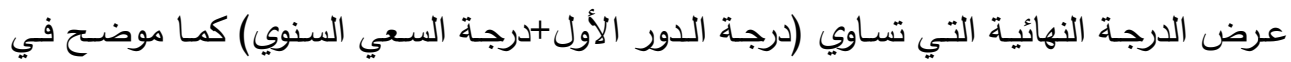
الثاشة (14): (14) 


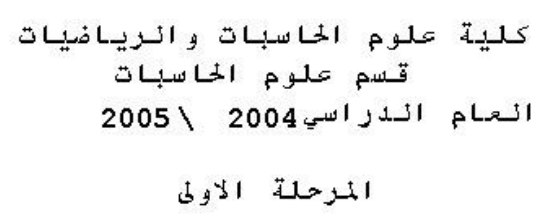

\begin{tabular}{|c|c|c|}
\hline انسد,ر الاوث & الاسم الـثلاثشي & 3 \\
\hline 7.00 & احمل امن عمسل & 1 \\
\hline 34.00 & أحخد سلـيبهان د داؤد & 2 \\
\hline 42.00 & أحمد طلاث سلـطان أحمل & 3 \\
\hline 41.50 & 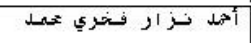 & 4 \\
\hline 54.00 & 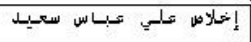 & 5 \\
\hline 53.50 & أرووى عوسين إلـيساس خضر & 6 \\
\hline
\end{tabular}

الثاشة (14) توضح تقرير درجة الدور الأول لمادة واحدة

أمسا بالنسبة للطلبة المكملين: فعند اختيار اسم أية مادة من المواد التي تقع تحت الدور الثاني يتم عرض نفس التقرير السابق مع اختلاف الحساب للدرجة النهائية التي تساوي (درجة الدور الثاني + درجة السعي السنوي). وعند اختيار مفتاح (قائمة المكملين) يتم عرض قائمة تحتوي على أسماء الطلبة المكملين للمستوى الذي يتم التعامل معه.

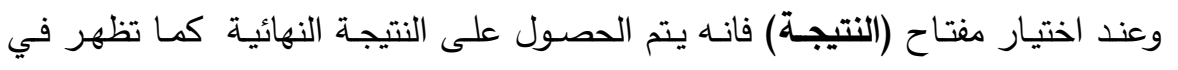
الثاشة (15) التي تحتوي على التقديرات التي حصل عليها الطالب. 


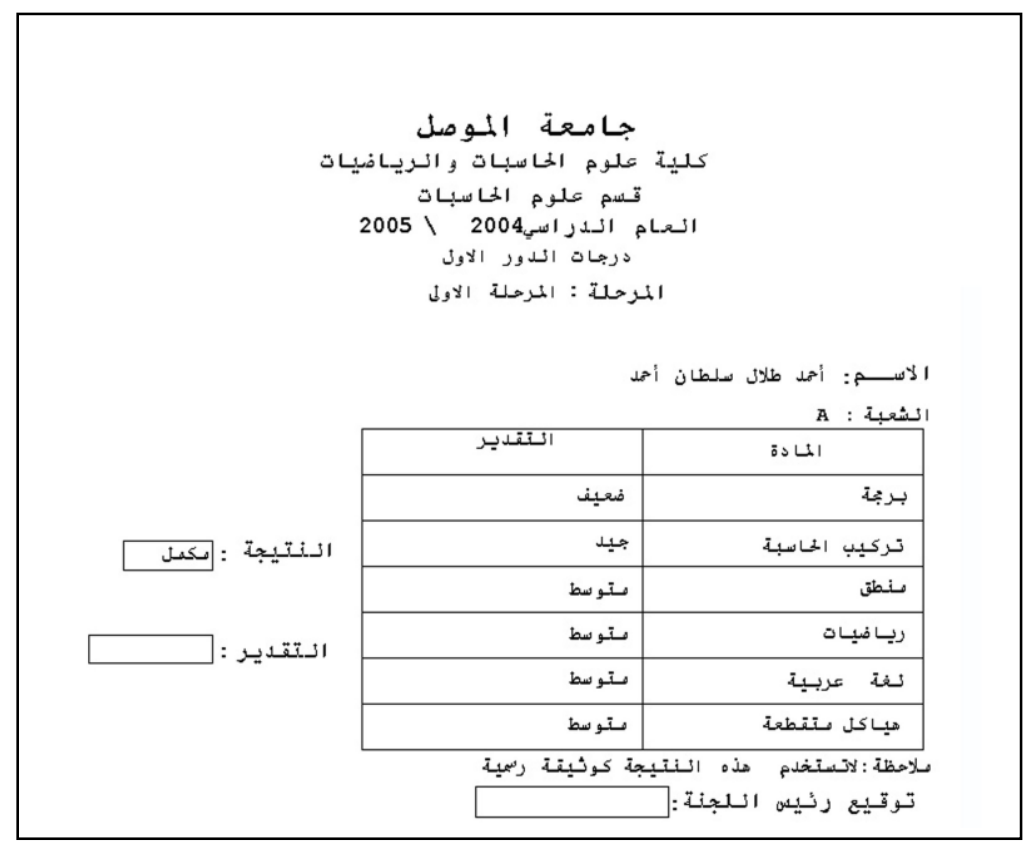

الشاشة (15) توضح نموذج نتيجة الطالب

أمـا عندما يتم اختيار المفتـاح (رجـوع) فانـه يتتم الخروج مـن الثاشـة (13) والعودة إلىى

الثاشة الرئيسية للمستوى الذي يتم التعامل معه والممثلة في الثاشة (4). 9. - التعامل مع جدول الارجات:

عند اختيار المفتاح (جدول الدرجات) الموجود في الثاشـة (4) فانـه يتم استدعاء الثاشـة (16) وعند اختيار اسم أية مادة من المواد يتم عرض تقرير يحتوي على أسماء الطلبة والدرجات (الفصل الأول، نصف السنة، الفصل الثاني، السعي السنوي، الامتحان النهائي للدور الأول، الدرجة الدئ النهائية، الامتحان النهائي للدور الثاني، الدرجة النهائية). 


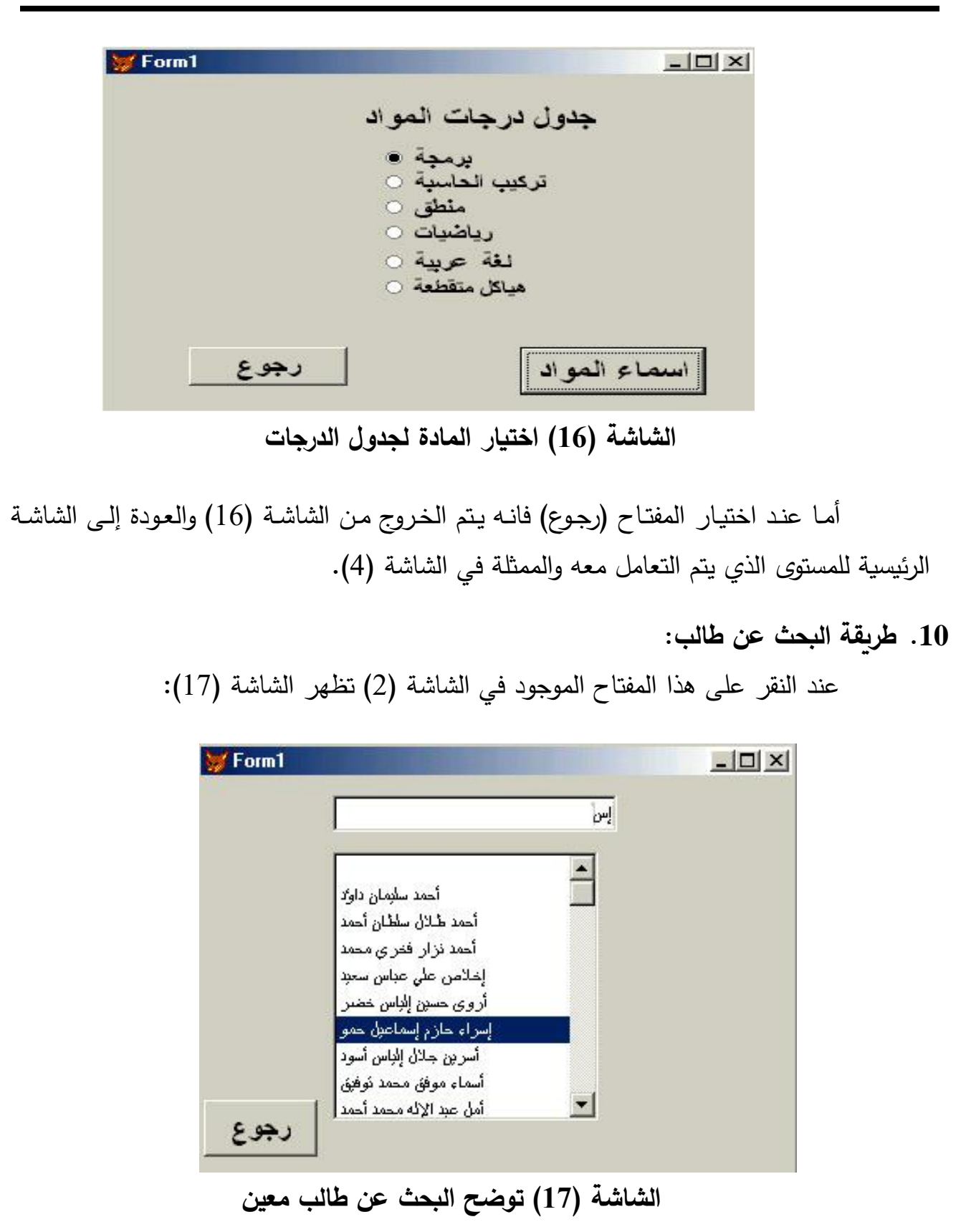


عـد البحث عن اسـ طالب معين يـتم إدخـال الحرف الأول مـن الاسم فتظهر جميع الأسماء التي تبدأ بهذا الحرف على القائعـة وعند إدخال الحرف الثاني تظهر الأسماء التي تبدأ بهذين الحرفين، وتكرر هذه الطريقة حتى يتم الوصول إلى الاسم المراد البحث عنه.

11. 11

عند النقر على مفتاح الإحصائيات الموضح في الثاشـة (2) سيتم المطالبة باختيار نوع الدراسـة (صـباحي أو مسـائي)، ثم بعد ذلك سـتظهر شاشـة تتكون مـن أربـع بطـائق وكل بطاقـة

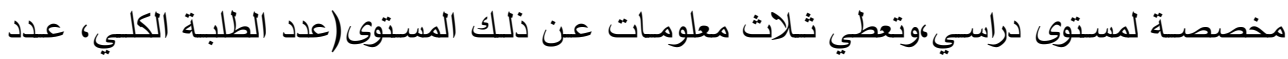
الناجحين، نسبة النجاح) كما هو موضح في الثاشة (18).

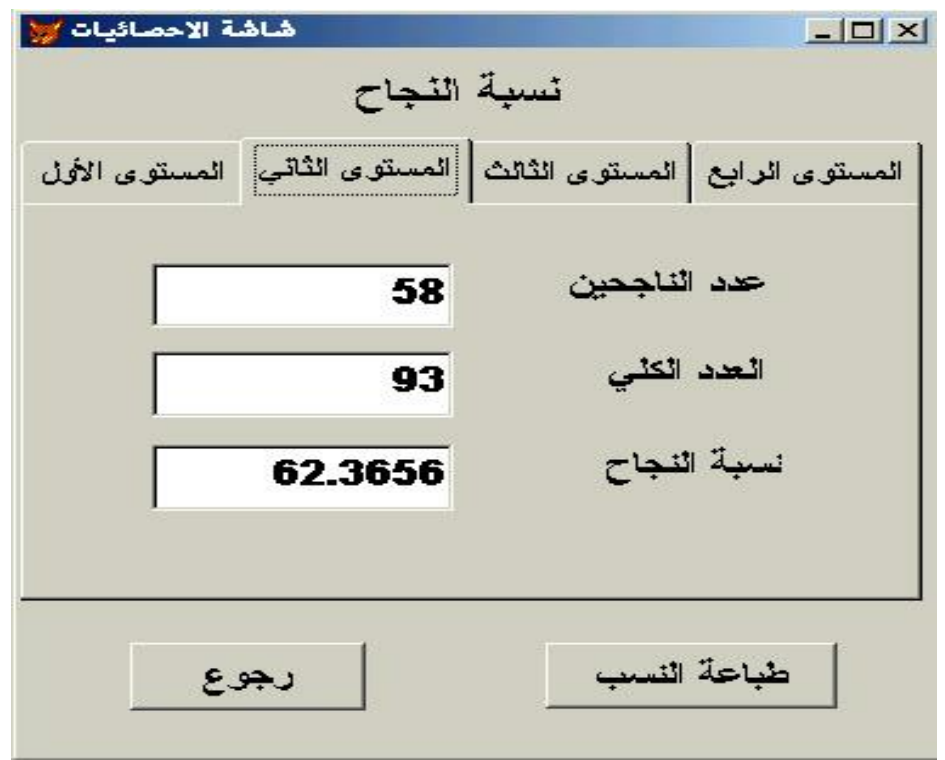

الثاشة (18) شاشة الإحصائيات

كما إن هذه الثاشة تحوي على مفتاح (طباعة النسب) الذي يمكن المستخدم من طباعة هذه النسب على الطابعة مع مجموع كل منها كما في الثاشة (19): 
عبد العزيز سليمان _طرفة ياسين حامد و نادية طارق صالح

\begin{tabular}{|c|c|c|c|c|}
\hline أَيـات & تقــريـر الV & & & \\
\hline تعبـا الـنجباح & الكعدد السكلي & الـنايعين & علد & \\
\hline 18.0000 & 100 & & 18 & المعتوى اللور \\
\hline 62.3656 & 93 & & 58 & المعتوى انـثاتي \\
\hline 73.6264 & 91 & & 67 & المعتوى انتـاثد \\
\hline 79.0000 & 100 & & 79 & |المعتوى الـر ايع \\
\hline 57.8125 & 384 & & 222 & الجمبوع \\
\hline
\end{tabular}

\section{الاستنتاجات \\ 1- 1 مرونة في عملية الإدخال:}

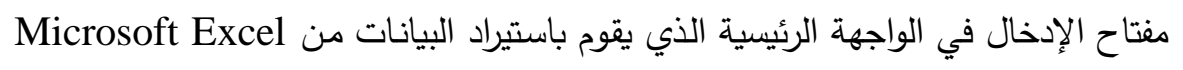

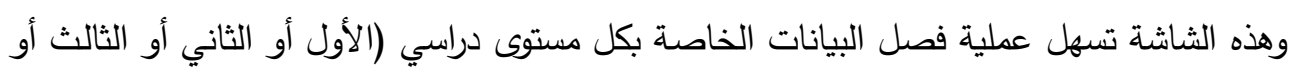

$$
\text { 2- قاريائم الدرجات: }
$$

من نتائج النظام هو الحصول على العديد من القوائم وهذه القوائم تضم أسماء الطلبة

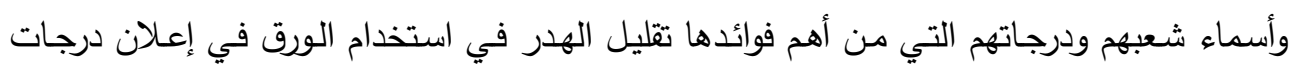

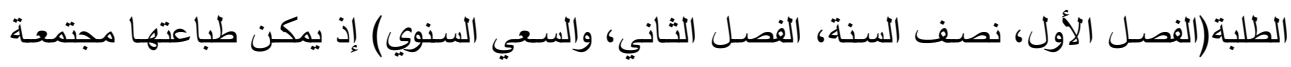

لجميع المواد بدلاً من طباعة درجات كل مادة بشكل مستقل.

3- 3 قائمة نتيجة الطالب:

وهذه القائمسة تمثل النتيجة النهائية للطلبة بعد أداء الامتحانات النهائية و تضم أسماء

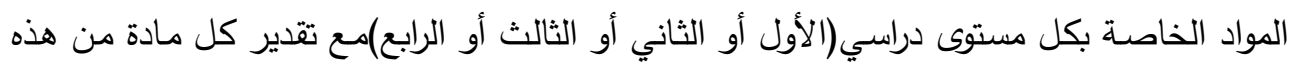

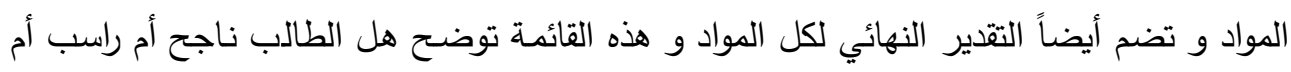
مكمل ومن أهم فوائدها هي السرعة في عملية سحب النتائج على الورق. 


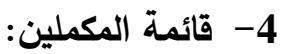

في هذه القائمة تظهر أسماء الطلبة المكملين في مادة واحدة أو أكثر و هذه العملية تسهل

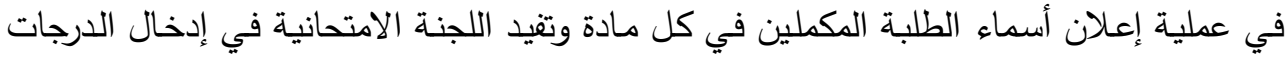
بعد امتحان الدور الثاني.

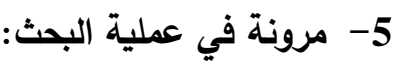

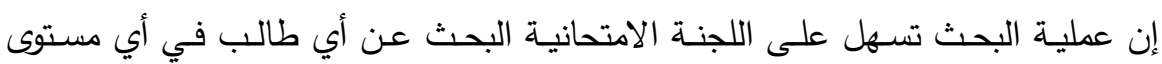
دراسي و في أية دراسة (صباحي أو مسائي)عن طريق إدخال الأحرف الأولى من اسمه.

\section{التوصيات}

1- تطوير النظام ليكون مستخدما على شبكة للحاسبات بحيث يمكن التعامل مع النظام من خلال

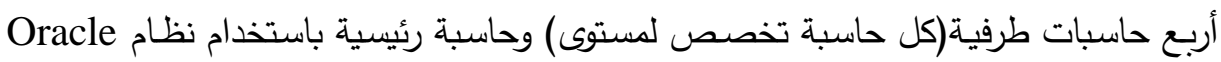
وبذلك نحقق سرعة في الاستفادة من النظام بنسبة كبيرة. 2- يمكن الاستفادة من البيانات النهائية التي نتجت لكل طالب لأرشفة معلومات بطاقة الطالب التي تمثل تأريخ الطالب منذ دخوله الكلية وحتى التخرج. 3- يمكن أن يكون العمل متداخلاً بين اللجنة الامتحانية والتسجيل من خلال إرسال أسماء الطلبة

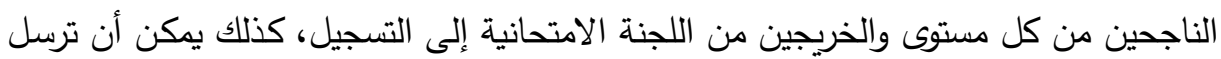
بيانات الطلبة المقبولين من التسجيل إلى اللجنة الامتحانية وهذا يتطلب أن يربط النظام على الإنى

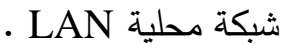




$$
\text { حسن، طارق. " أساسيات فيجوال فوكسبرو الاصدار الخامس"، دار الكتب العلمية للنشر }
$$

ريبر ، سوزان. كوليك، روبرت. "تعلم البرنامج 3.0 Visual FoxPro " الدار العربية

$$
\text { للعلوم، ترجمة مركز التعريب والبرمجة، } 1993 .
$$

[3] Bazian, M.; C. Silver, ; J. Booth, ; J. Long, ; V. Miller, and R. Byers (1999),"Special Edition Using Visual FoxPro 6", Que Corporation.

[4] http://www.moe.edu.kw/schools-2/mobarak_alkabeer/kinderschools /albahaakg /prjgoal.htm

[5] http://www.swmsa.com/forum/showthread.php?p=20045\#post20045

[6] http://www.uiowa.edu/ idt/courses/7W135/StudentLinks/Link3/Co mputerManagedInstruction.html. 